\title{
STABILITY AND INTEGRATION OF LASER SINTERED VERSUS SANDBLAST ACID ETCHED IMPLANTS
}

\author{
Ahmad A. H. El-Feky*
}

\begin{abstract}
Objectives: to evaluate clinically and radiographically stability and tissue integration of laser sintered implant and acid etched-sandblasted implant.

Subjects and methods: Ten implants were inserted in patients with unrestorable premolar or molar teeth indicated for extraction. They were divided into two groups as the following: group A included patients who received dental implants with Laser- treated surface, group B included patients who received implants with (SLA) sandblasted-acid etched surface. The patients were clinically and radiographically evaluated preoperatively and postoperatively at the intervals of 4 month, 6 and 9 months. Clinical evaluation included pocket depth, gingival health, implant stability using osstell, bleeding index, plaque index, pain and satisfaction. Radiographic evaluation was done by using periapical radiographs to measure the marginal bone defect.
\end{abstract}

Results: Both Laser- treated surface implants and sandblasted-acid etched surface implants have significant success rates with superior clinical and radiographic results of laser treated implants over acid etched implants after a follow up period up to 9 months.

Conclusion: Laser and acid etched treatment are promising methods for roughening the implant surface and both have significant success rates.

KEY WORDS: Laser treated, Acid etched, Dental implants.

\section{INTRODUCTION}

Osseointegration is a direct structural and functional connection between living bone and the surface of a load-carrying implant. Creation and maintenance of osseointegration depends on the understanding of the tissue healing, repair, and remodeling capacities ${ }^{(1)}$. Several important factors affect the mechanical stability and osseointegration of the implant. These factors are the biocompatible material of the implant (2), atraumatic surgery to minimize tissue damage ${ }^{(3)}$, implant placement in intimate contact with bone and immobility of the implant during the healing period ${ }^{(4)}$. Other factors may be surface composition, topography, roughness and surface energy ${ }^{(5)}$.

\footnotetext{
* Assistant Professor of Oral and Maxillofacial Surgery Department, Faculty of Dental Medicine for Boys, Al-Azhar University, Cairo, Egypt.
} 
Surface treatment of the implant is one of the important criteria for stability and osseointegration. Plasma spray ${ }^{(6)}$, acid etching, dual acid etching (DAE), sand blast acid etching (SLA) ${ }^{(7)}$ in addition to laser sintering has been used as a modification in surface design.

Plasma spray coating such as hydroxyapatite (HA) and titanium (Ti) spraying has been used in several studies. HA coated titanium implant could enhance the healing period compared to the uncoated implants and promote better cell proliferation ${ }^{(8,9)}$.

Implant treatment with acid and dual acid etching (DAE) has been via chemical or acid or with the combination of both. Rapid osseointegration can be achieved by dual etching through micro rough surface $^{(10,11)}$. Surfaces which have been blasted prior to acid etching will generally show irregular surface topography ${ }^{(12)}$. This can increase the rate and amount of bone formation on the implant surface via attraction body fluids to the surface of the implant, accelerating growth and reducing the possibility of infection ${ }^{(13)}$.

The implant surface is blasted with Alumina of 250 to $500 \mu \mathrm{m}$ followed by acid-etching using sulfuric or hydrochloric acid to construct porous structures which can be tailored to match human cortical bone as that occur in Direct metal laser sintering (DMLS) ${ }^{(14,15)}$. DMLS is a laser-based additive manufacturing technique, in which an object is built layer by layer using powdered metals, radiant heaters, and a computer-controlled laser. Basically, the machine produces the object on a moveable platform by applying incremental layers of the pattern material. This is an important advantage that may allow bone ingrowth and vascularization, thus enhancing osseointegration and long-term reliability of an implant ${ }^{(16,17)}$. By using (DMLS), it is easy to create porosity which can be tailored to match human cortical bone ${ }^{(18,19)}$.The present study compared the effect of SLA and DMLS implants on stability and success of the implant.

\section{PATIENTS AND METHODS}

This is a randomized controlled clinical study, which included ten implants were inserted in patients of both sexes with an average age ranging between 20 to 55 years with unrestorable teeth indicated for extraction in premolar and molar regions. They were selected from the Outpatient Clinic of Oral and Maxillofacial Surgery Department at Faculty of Dental Medicine, Al- Azhar-University, Boys, Cairo. These patients were randomly assigned to one of two groups (group A or group B); ten patients were allocated in each group, patients in group A received laser treated implants, while those in group $B$ received conventional acid etched implants. The inclusion criteria of this study were; patients with unrestorable teeth indicated for extraction, Patient age ranged from 20 to 55 years old and with good oral hygiene. While the exclusion criteria were patients with uncontrolled medically compromised states that affect bone healing or suffering from uncontrolled bleeding or coagulating disorder or heavy smoker and mentally challenged patients. Patients were fully informed about the treatment procedures and follow up examination. Appropriate institutional ethical clearance and written informed consent were obtained.

\section{Preoperative evaluation}

- Clinical assessment of patient's past medical history, oral condition, evaluation of the implant site by digital examination of the covering mucosa and applying finger pressure, to detect sharp ridges, tender areas or extremely thin mucosa.

- Radiographic evaluation including preoperative digital panoramic and periapical radiographs were taken to verify the bone height and the implantation site. (Fig. 1a)

\section{Surgical procedure}

All patients were instructed to use chlorhexidine mouth rinse regularly. The day before surgery, 
patients received a suitable prophylactic. Also, analgesic has been taken if necessary. Local anesthesia was induced with Mepivacaine/ levonordefrin. After anesthesia was secured, a crestal incision was made, at the site of the tooth to be replaced. A full thickness mucoperiosteal flap was reflected buccally. Drilling was done with a low speed high torque externally irrigated contra-angle handpiece with a surgical motor unit. The implant position was marked with a round bur, Sequential drilling was accomplished first with pilot drill. The Standard drilling sequence for the implant started from the pilot drill, an intermediate drill, and then ended with the final drill. Parallel pin was used to check the orientation of an osteotomy .It was used to gauge parallelism. The sealed sterile implant package was opened and the implant with its attached insertion tool was removed from the inner vial and carried to the prepared osteotomy site. Implant placement (Fig. 1b) was done at torque $35 \mathrm{ncm}$, osstell was used to evaluate primary stability, cover screw was used (Fig. 1c). Patients will be instructed to avoid any trauma at the implant area. The surgical site was irrigated with sterile saline solution and the mucoperiosteal flap was repositioned to its original site and sutured using 3-0 black silk. (Fig. 1d)

\section{Post-surgical care}

Postoperative antibiotics and analgesics were prescribed. Patients were instructed for maintaining good oral hygiene with Chlorhexidine HCL $(0.12 \%)$. All patients were instructed to have a soft diet for the first week. For those having bilateral implants; soft diet was maintained for 3 weeks.

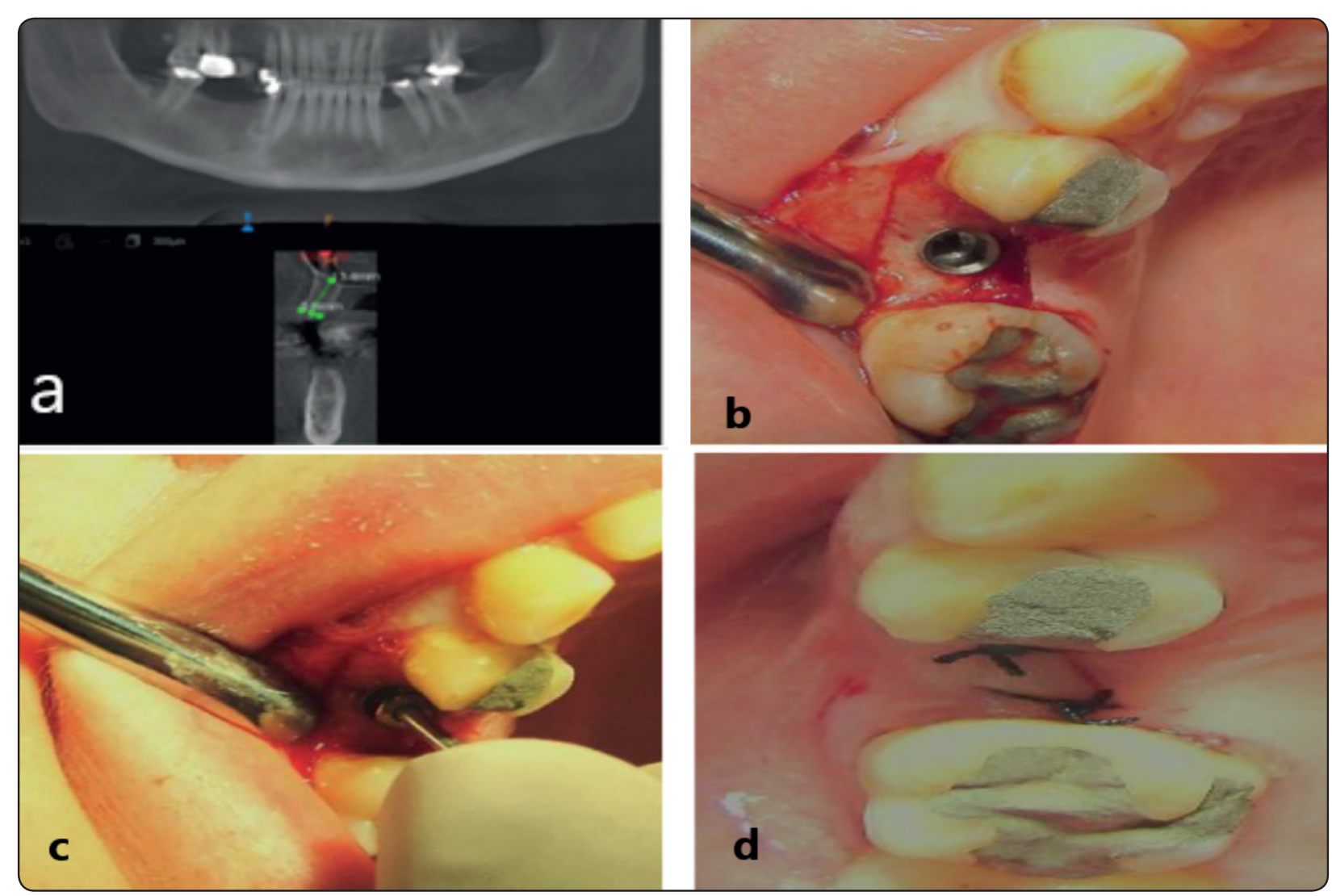

Fig. (1) (a) Preoperative panorama showing missing maxillary right premolar. (b) A photograph showing implant insertion. (c) A photograph showing the tightened cover screw. (d) A photograph showing the flap closure. 


\section{Prosthetic phase}

Suture removal was performed after 8-10 days. At 4 months, a definitive abutment level impression was made and acrylic restorations were cemented to the abutments.

\section{Post-operative assessment}

Clinical and radiographic evaluation were done to all cases at 4, 6 and 9 months postoperatively, as the following:

\section{A) Clinical evaluation}

All patients were examined at the intervals of four, six and nine months to check for the presence of pain, discomfort, swelling, or infection. Then, the probing pocket depth, plaque index, modified sulcus bleeding index and gingival recession were measured to clinically evaluate the cases at the same intervals. Also, implant stability was assessed at the same follow up visits by using Resonance Frequency Analysis (RFA) by Osstell which was expressed by ISQ scale.

\section{B) Radiographic evaluation}

Standardized periapical radiographs were taken preoperatively and after 4, 6 and 9 months to evaluate changes of marginal bone level around the dental implant. (Fig. 2a-2c)

\section{Statistical analysis}

The collected data were coded, processed and analyzed using the SPSS (Statistical Package for Social Sciences) version 22. Quantitative data were expressed as mean \pm SD (Standard deviation) and median (range). Independent samples t-test was used to compare between two independent groups of normally distributed variables (parametric data) while Mann Whitney U test was used for nonnormally distributed Data (non-parametric data).
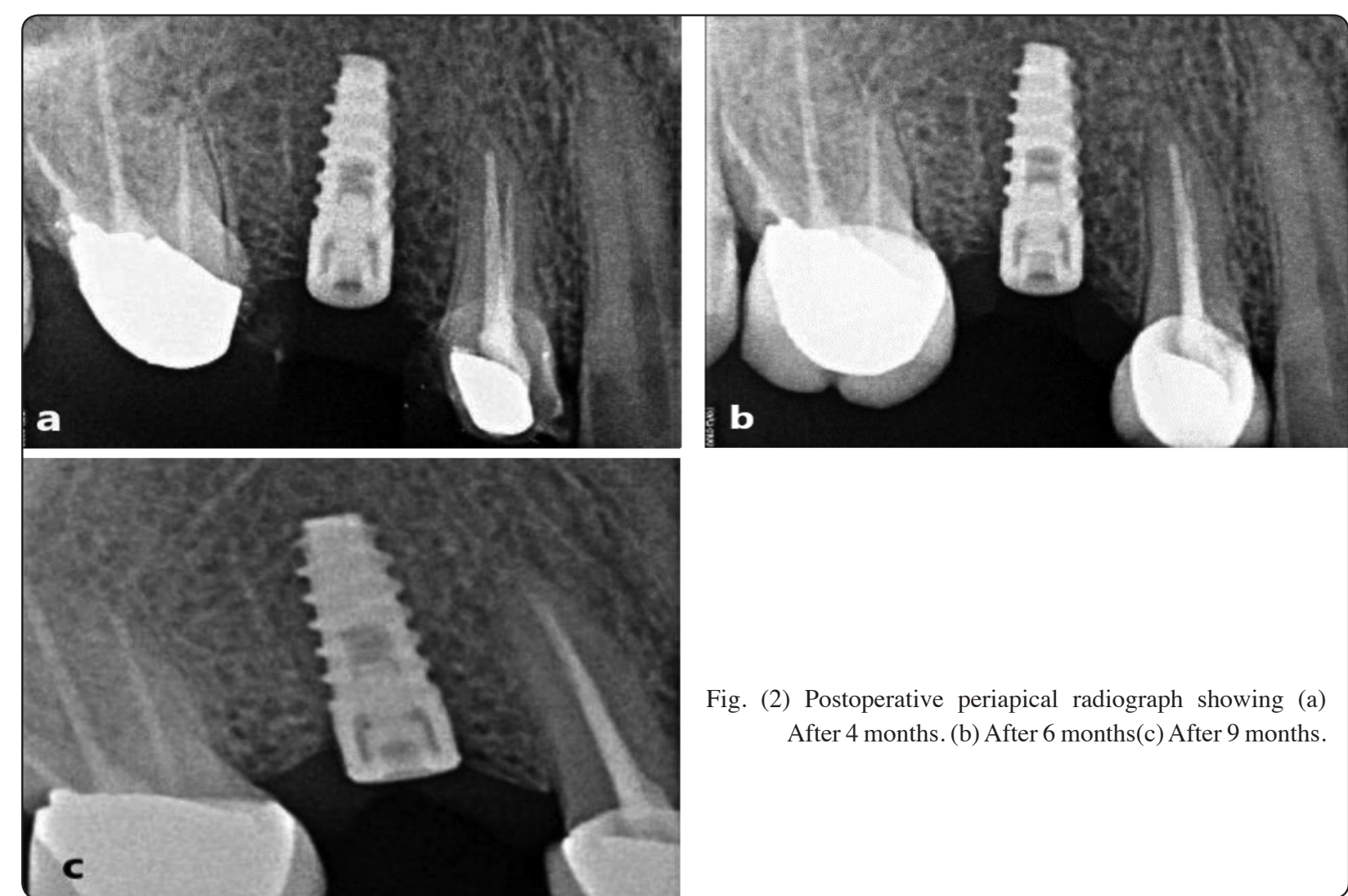

Fig. (2) Postoperative periapical radiograph showing (a) After 4 months. (b) After 6 months(c) After 9 months. 
For comparison of data at two different time points, paired samples t-test was used to compare between two related groups of normally distributed variables (parametric data) while Wilcoxon Signed Rank test was used for non-normally distributed Data. P value $\leq 0.05$ was considered statistically significant.

\section{RESULTS}

All patients were subjected to clinically and radiographically follow up visits at 4,6 and 9 months.

\section{Clinical evaluation}

\section{- Peri-implant pocket depth:}

It was measured to the nearest $\mathrm{mm}$ with a periodontal probe. The mean and standard deviation for probing depth values were calculated in both groups at 4, 6 and 9 months. They were $0.88 \pm 0.38$, $1.38 \pm 0.38$ and $1.68 \pm 0.41$ at 4,6 and 9 months respectively in group A and were $1.50 \pm 0.38$, $1.72 \pm 0.23$ and $1.78 \pm 0.23$ at 4,6 and 9 months respectively in group B. The difference between the two groups was found to be statistically significant at 4 months $(p=0.03)$ and insignificant at 6 and 9 months. (Table 1)

- Gingival recession: There was no detected gingival recession in both groups.

- Implant stability: It was measured by Resonance Frequency Analysis (RFA) by Osstell. The score indicates the Implant Stability Quotient scale (ISQ). The mean ISQ values for group $\mathrm{A}$ at 4, 6 and 9 months were $89 \pm 6.24$, $82.20 \pm 4.44$ and $87.60 \pm 6.07$ respectively. While the mean ISQ values for group B at 4, 6 and 9 months were $87 \pm 5.87,82.40 \pm 4.56$ and $84 \pm 4.85$ respectively. These values showed initial drop in ISQ values at 6 months follow up in both groups with gradual increase in the 9 months follow up visit. Although the elevation in ISQ values in group A more than in group $\mathrm{B}$ but there was no statistically significant difference between them.

\section{Radiographic evaluation:}

Marginal bone defect was measured and the mean of all these values was calculated for each group at 4,6 and 9 months. The mean values with standard deviation of MBD in group A were 0.64 $\pm 0.11,0.98 \pm 0.08$ and $1.24 \pm 0.11$ at 4,6 and 9 months respectively. While the mean values of MBD in group B at 4, 6 and 9 months were 0.66 $\pm 0.11,1.16 \pm 0.05$ and $1.38 \pm 0.08$ respectively. The difference in marginal bone defect values between the two groups was found to be statistically significant at 6 months $(P=0.004)$ and insignificant in 4 and 9 months.

Comparing evaluation criteria at different time intervals: For each group, values of evaluation parameters at 4 months were compared with those at 6 and 9 months. In group A: as in - Implant stability: There was a high significant difference on comparing implant stability by osstell at 4 months with that at 6 months, 4 months with that at 9 months and 6 months with that at 9 months $(\mathrm{P} 1=0.004, \mathrm{P} 2=0.025, \mathrm{P} 3=0.009)$ respectively. - Peri-implant probing depth: There was a highly significant statistical difference on comparing periimplant probing depth at 4 months with that at 6 months and at 4 months with that at 9 months $(\mathrm{P} 1=$ $0.025, \mathrm{P} 2=0.042$ ) respectively. Comparing probing depth at 6 months with that at 9 months, there was no statistically significant difference $(\mathrm{P} 3=0.109)$. Marginal bone defect: There was a highly significant difference on comparing marginal bone defect at 4 months with that at 6 months, 4 months with that at 9 months and 6 months with that at 9 months $(\mathrm{P} 1=$ $0.031, \mathrm{P} 2=0.019, \mathrm{P} 3=0.043)$ respectively. Table (1) While, in group B: as in - Implant stability: There was a high significant difference on comparing implant stability by osstell at 4 months with that at 6 months, 4 months with that at 9 months and 6 months with that at 9 months $(\mathrm{P} 1=0.011, \mathrm{P} 2=$ $0.019, \mathrm{P} 3=0.022)$ respectively. $\bullet$ Peri-implant 
probing depth: There was no significant statistical Marginal bone defect: There was a highly significant difference on comparing peri-implant probing depth difference in comparing marginal bone defect at 4 at 4 months with that at 6 months, at 4 months with months with that at 6 months, 4 months with that at that at 9 months and 6 months with that at 9 months 9 months and 6 months with that at 9 months $(\mathrm{P} 1=$ $(\mathrm{P} 1=0.059, \mathrm{P} 2=0.062, \mathrm{P} 3=0.083)$ respectively. $\bullet \quad 0.025, \mathrm{P} 2=0.011, \mathrm{P} 3=0.045)$ respectively. Table $(2)$

TABLE (1) Comparing the evaluation parameters at different follow up visits in group A (Laser):

\begin{tabular}{|c|c|c|c|c|}
\hline Test of significance & 9 months & 6 months & 4 months & \\
\hline \multicolumn{5}{|c|}{ Implant stability } \\
\hline $\mathrm{P} 1=0.004^{*}$ & $87.60 \pm 6.07$ & $82.20 \pm 4.44$ & $89 \pm 6.24$ & Mean \pm SD \\
\hline $\begin{array}{l}\mathrm{P} 2=0.025^{*} \\
\mathrm{P} 3=0.009^{*}\end{array}$ & $89(77-92)$ & $83(75-87)$ & $92(78-93)$ & Median(min-max) \\
\hline \multicolumn{5}{|c|}{ Peri-implant probing depth } \\
\hline $\mathrm{P} 1=0.025^{*}$ & $1.68 \pm 0.41$ & $1.38 \pm 0.38$ & $0.88 \pm 0.38$ & Mean \pm SD \\
\hline $\begin{array}{l}\mathrm{P} 2=0.042 * \\
\mathrm{P} 3=0.109 *\end{array}$ & $1.9(1-2)$ & $1.3(1-2)$ & $0.8(0.5-1.5)$ & $\operatorname{Median}(\min -\max )$ \\
\hline \multicolumn{5}{|c|}{ Marginal bone defect } \\
\hline $\mathrm{P} 1=0.031 *$ & $1.24 \pm 0.11$ & $0.98 \pm 0.08$ & $0.64 \pm 0.11$ & Mean \pm SD \\
\hline $\begin{array}{l}\mathrm{P} 2=0.019^{*} \\
\mathrm{P} 3=0.043^{*}\end{array}$ & $1.2(1.1-1.4)$ & $1(0.9-1.1)$ & $0.6(0.5-0.8)$ & $\operatorname{Median}(\min -\max )$ \\
\hline \multicolumn{3}{|c|}{ p: intergroup significance } & \multicolumn{2}{|c|}{ p1: significance between 4th month and 6th month } \\
\hline $\begin{array}{l}p 2: \text { significance } b \\
*: \text { statistically sign }\end{array}$ & $\begin{array}{l}\text { Ath month an } \\
(p<0.05)\end{array}$ & & \multicolumn{2}{|c|}{ p3: significance between 6th month and 9th month } \\
\hline
\end{tabular}

TABLE (2): Comparing the evaluation parameters at different follow up visits in group B (Acid etched):

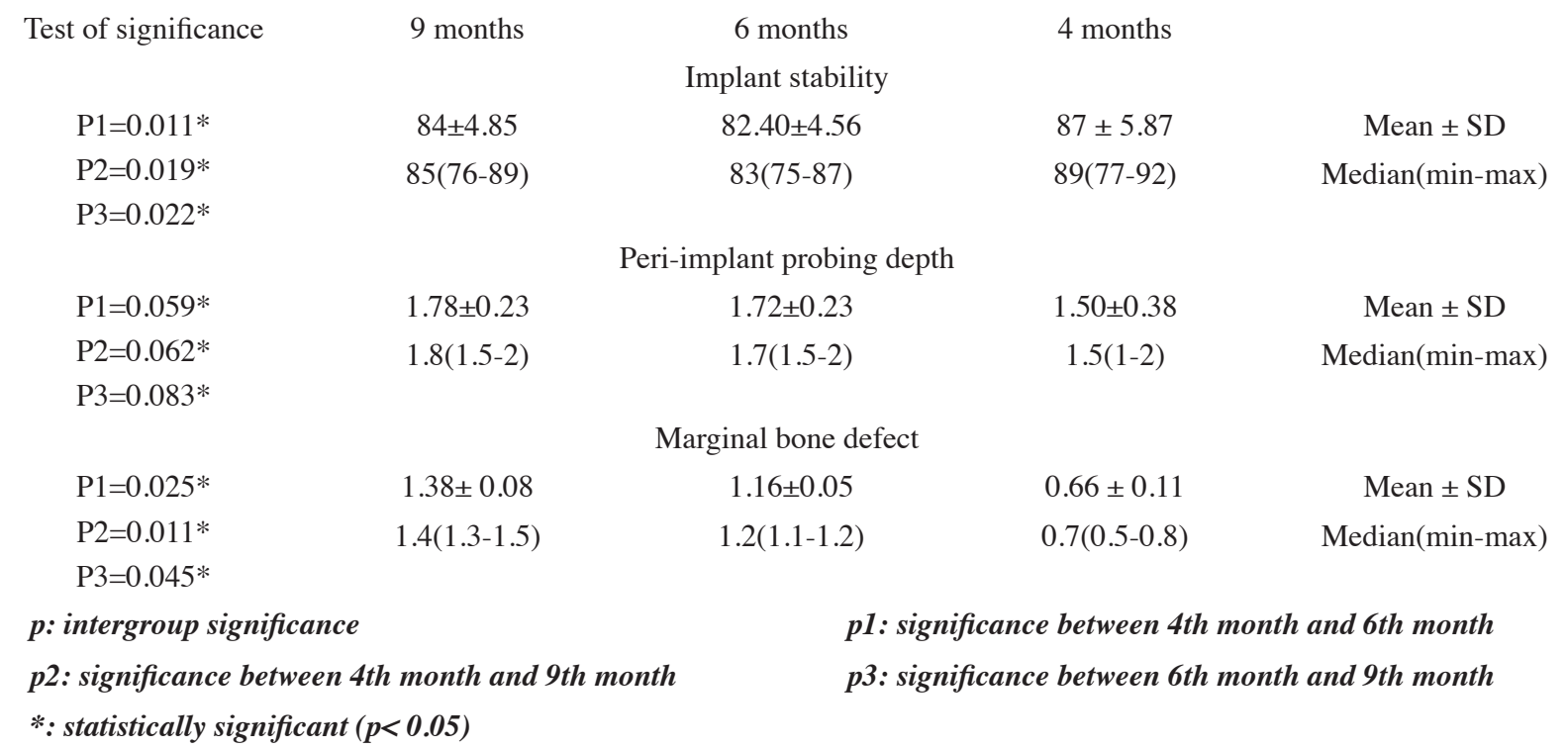




\section{DISCUSSION}

Many studies recognized that the implant surface is an important factor influencing osseointegration. Several research groups were done to examine new titanium surfaces and focused on subtractive surface techniques such as sandblasting and/or acid-etching procedures ${ }^{(20-23)}$.

Osseointegration of dental implants became a synonym for the biomechanical concept of secondary stability. Secondary stability of a dental implant largely depends on the degree of new bone formation at the bone-to-implant interface ${ }^{(20)}$.

Regarding the implant stability, in both groups, regardless the type of surface treatment, there was an initial drop in the resonance frequency analysis by Osstell (ISQ) followed by elevation to levels close to those at time of installation. It was found that the mean of ISQ values at time of installation (4 month) was $89 \pm 6.24$ for group A and $87 \pm 5.87$ for group B while at 6 months the mean of ISQ values for group A was $82.20 \pm 4.44$ and $82.40 \pm 4.56$ for group B, at 9 months mean of ISQ values was 87.60 \pm 6.07 for group A and $84 \pm 4.85$ for group B. This was in agreement with the study performed by Kim et al. in $2010^{(24)}$ which demonstrated that there was a changing pattern of ISQ values that slightly decreased at the first follow up post-implantation and increased thereafter. In agreement with this study, Lee and Cho in $2016^{(25)}$ found that there was a slight increase in ISQ values in Laser treated implants in comparison with SLA implants but with no statistically significant difference.

This study compared the marginal bone defect values between the two groups. At 4 months postoperatively the difference in marginal bone defect values between the two groups was found to be statistically insignificant, at 6 months the difference in marginal bone defect values was found to be statistically significant and at 9 months the marginal bone defect values were lower in group $\mathrm{A}$ in comparison with group B but with no statistically significant difference. The radiographic bone level changes from 4 months resulted in a mean bone defect of $0.64 \mathrm{~mm}$ for the Laser group and it was 0.98 and 1.24 at 6 and 9 months respectively. The mean bone defect for acid treated implants was $0.66,1.16,1.38$ at 4, 6, 9 months respectively and this agrees with the research done by Halwag et al. in $2015^{(19)}$.

Considering the peri-implant pocket depth, at 4 months, the mean of peri-implant probing depth in group A was 0.88 and 1.50 in group $B$ which showed statistically significant difference $(P=0.032)$. At 6 and 9 months, mean peri- implant probing depth was 1.38 and 1.68 respectively for group A. While the mean for group B at 6 and 9 months was 1.72 and 1.78 respectively which showed no statistically significant difference between both groups. This was in agreement with Chen et al study in 2017 (26) which was a systematic review and meta-analysis which demonstrated that Peri-implant probing depth around Laser treated implants was shallower than a roughed and machined surface implants.

In our study the results indicated that osseointegration was better in laser treated implants in comparison with acid etched implants. This was in agreement with the results of Trisi et al. In $2016^{(27)}$ they found that Laser treated surface implants have a higher osteoconductive and allowed a strong osseointegration in poor-quality bone than machined surface implants.

Also, in agreement with a study done by Faeda et al. in $2009^{(28)}$ which revealed that the laser-treated group achieved higher removal torque values when compared to the machined control group. Moreover, the results suggest that the machined implants had a time-dependent anchorage, while the laser-treated implants had an acceleration of this process. Thus, it is possible that the stronger bone integration with laser grooved surfaces observed in the current study is not only due to a rougher surface, but may also be due to a more favorable surface chemistry than that of the machined surface. 
In contrast to our study, Rong et al. in $2018^{(29)}$ performed a Comparison of early osseointegration between laser-treated and acid-etched titanium implant surfaces and revealed that both exhibited good osseointegration. Although the laser treated surface implant was cleaner and more uniform than the acid etched surface implant, there were no significant differences found between both.

Also, De Tulle et al. study in $2020^{(30)}$ made a comparative evaluation among laser treated, machined, and acid etched implant surfaces on sheep and observed good osseointegration in both acid etched and laser surface implant with no significant differences in the bone to implant contact percentage comparing acid-etched and laser-treated surface implants.

As regarding plaque index and modified bleeding index, this study found that the difference in plaque index and modified bleeding index values between the two groups was found to be statistically insignificant in all follow up visits.

\section{CONCLUSION}

The present study showed that both Laser and acid etched treatment are promising methods for roughening the implant surface and both have significant success rates with superior clinical and radiographic results of laser treated implants over acid etched implants after a follow up period up to 9 months. Although, follow- up period of 9 months following implant placement seems to be not enough to determine definitive superiority of implant type on the other; a longer period is recommended.

\section{REFERENCES}

1. Vinathi-Reddy K. Osseointegration. Int Dent Med J Advanced Res 2015; 1: 1-7.

2. Saini M, Singh Y, Arora P, Arora V, Jain K. Implant Biomaterials: A Comprehensive Review. World J Clin Cases. 2015; 3: 52-57.

3. Tavarez Rr, Reis Wl, Rocha AT, Firoozmand Lm, Bandéca Mc, Tonetto Mr Et Al. Atraumatic Extraction and Imme- diate Implant Installation: The Importance of Maintaining The Contour Gingival Tissues. J Int Oral Health .2013; 5: 113-118.

4. Raghavendra S, Wood Mc, Taylor Td. Early Wound Healing Around Endosseous Implants: A Review of the Literature. Int J Oral Maxillofac Implants 2005; 20: 425- 431.

5. Parekh Rb, Shetty O, Tabassum R. Surface Modifications for Endosseous Dental Implants. Int J Oral Impl Clin Res .2012; 3: 116-121.

6. Junker R, Dimakis A, Thoneick M, Jansen Ja. Effects of Implant Surface Coatings and Composition On Bone Integration: A Systematic Review. Clin Oral Impl Res. 2009; 20: 185-206.

7. Coelho P, Granjeiro J, Romanos G, Suzuki M, Silva N, Cardaropoli G, Thompson V, Lemons J. Basic Research Methods and Current Trends of Dental Implant Surfaces. Biomed Mater Res Part B Appl Biomater .2009; 88: 579-596.

8. Liu X, Poon R, Kwok S, Chu P, And Ding C. Plasma Surface Modification of Titanium for Hard Tissue Replacements. Surf Coat Technol .2004; 186: 227-233.

9. Jemat A, Ghazali M.J, Razali M, Otsuka Y. Surface Modifications and Their Effects On Titanium Dental Implants. Biomed Res Int .2015; 2015: 1-11.

10. Vanzillotta P, Soares G, Bastos I, Simao R, Kuromoto N. Potentialities of Some Surface Characterization Techniques for The Development of Titanium Biomedical Alloys. Mat Res .2004; 7: 437-444.

11. Alla RK, Ginjupalli K, Upadhya N, Shammas M, Ravi R.K, Sekhar R. Surface Roughness of Implants: A Review. Trends Biomater Artif Organs .2011; 25: 112- 118.

12. Mendonça G, Mendonça D, Araga o F, Cooper L. Advancing Dental Implant Surface Technology from Micron to Nanotopography: A Review. Biomater .2008; 29:3822-3835.

13. Scarano A, Piattelli A, Quaranta A, Lorusso F. Bone Response to Two Dental Implants with Different Sandblasted/Acid-Etched Implant Surfaces: A Histological and Histomorphometrical Study In Rabbits. Biomed Res Int. 2017; 2017: 1-8.

14. Koshy E, Philip Sr. Dental Implant Surfaces: An Overview. Int J Clin Impl Dent. 2015; 1: 14-22.

15. Barfeie A, Wilson J, Rees J. Implant Surface Characteristics and Their Effect On Osseointegration. Br Dent J .2015; 218: 1-9. 
16. Mullen L, Stamp R, Brooks W, Jones E, Sutcliffe C. Selective Laser Melting: A Regular Unit Cell Approach for The Manufacture of Porous, Titanium, Bone In-Growth Constructs, Suitable for Orthopedic Applications. J Biomed Mater Res Part B App Biomater. 2009; 89: 325-334.

17. Dabrowski B, Swieszkowski W, Godlinski D, Kurzydlowski K. Highly Porous Titanium Scaffolds for Orthopaedic Applications. J Biomed Mater Res Part B Appl Biomater .2010; 95: 53-61.

18. Kang Ns, Li Lj, Cho Sa. Comparison of Removal Torques Between Laser-Treated and Sla-Treated Implant Surfaces in Rabbit Tibiae. J Adv Prosthod . 2014; 6: 302- 308.

19. Halwag A, El Prince N, Eldibany R. Comparative Study Between Laser Sintered Implant and Acid Etched Implant Seated in The Maxillary Premolar Area. Alex Dent J. 2015; 40: 186-91.

20. Buser D, Schenk Rk, Steinemann S, Fiorellini Jp, Fox Ch, Stich H. Influence of Surface Characteristics On Bone Integration of Titanium Implants. A Histomorphometric Study in Miniature Pigs. J Biomed Mater Res .1991; 25: 889- 902.

21. Cochran Dl, Schenk Rk, Lussi A, Higginbottom Fl, Buser D. Bone Response to Unloaded and Loaded Titanium Implants with A Sandblasted and Acidetched Surface: A Histometric Study in The Canine Mandible. J Biomed Mater Res . 1998; 40: 1-11.

22. Buser D, Nydegger T, Hirt Hp, Cochran Dl, Nolte LP. Removal Torque Values of Titanium Implants in The Maxilla of Miniature Pigs. Int J Oral Maxillofac Implants .1998; 13: 611-619.

23. Gotfredson K, Wennerberg A, Johansso C, Skovgaard Lt, Hjorting-Hansen E. Anchorage of Tio2-Blasted, Ha-Coat- ed, And Machined Implants: An Experimental Study with Rabbits. J Biomed Mater Res .1995; 29: 1223-1231.

24. Kim SJ, Kim Mr, Rim JS, Chung Sm, Shin Sw. Comparison of Implant Stability After Different Implant Surface Treatments in Dog Bone. J Appl Oral Sci .2010; 18: 415-420.

25. Lee JT, Cho Sa. Biomechanical Evaluation of LaserEtched Ti Implant Surfaces Vs. Chemically Modified Sla Ti Implant Surfaces: Removal Torque and Resonance Frequency Analysis in Rabbit Tibias. J Mech Behav Biomed Mater .2016; 61: 299- 307.

26. Chen Z, Zhang Y, Li J, Wang H1, Yu H. Influence of LaserMicrotextured Surface Collar On Marginal Bone Loss and Peri-Implant Soft Tissue Response: A Systematic Review and Meta-Analysis. J Periodontol .2017; 88: 651-662.

27. Trisi P, Berardini M, Colagiovanni M, Berardi D, Perfetti G. Laser-Treated Titanium Implants: An in Vivo Histomorphometric and Biomechanical Analysis. Implant Dent .2016; 25:575-580.

28. Faeda RS, Tavares Hs, Sartori R, Guastaldi AC, Marcantonio JE. Evaluation of Titanium Implants with Surface Modification by Laser Beam: Biomechanical Study In Rabbit Tibias. Braz Oral Res .2009; 23: 137-143.

29. Rong M, Lu H, Wan L, Zhang X, Lin X, Li S, Et Al. Comparison of Early Osseointegration Between Laser-Treated/ Acid-Etched and Sandblasted/Acid-Etched Titanium Implant Surfaces. J Mater Sci Mater Med .2018; 29:1-6.

30. De Tullio I, Berardini M, Di Iorio D, Perfetti F, Perfetti G. Comparative Evaluation Among Laser-Treated, Machined, And Sandblasted/Acid-Etched Implant Surfaces: An in Vivo Histologic Analysis On Sheep. Int J Implant Dent .2020; 6: 1-8. 